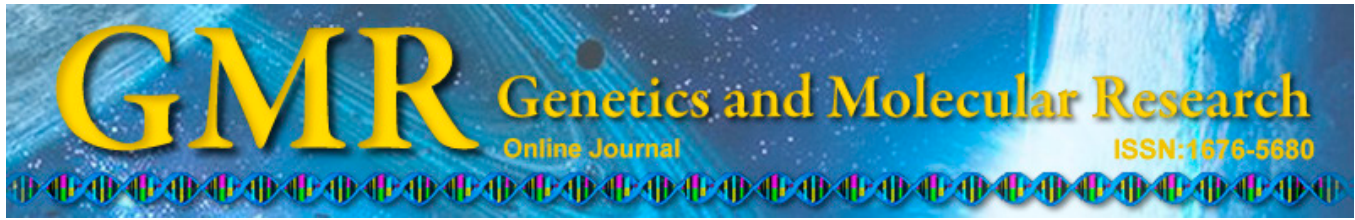

\title{
Association of the $V R K 2$ gene rs3732136 polymorphism with schizophrenia in a Northwest Chinese Han population
}

B. Zhang ${ }^{1}$, C.Y. Gao' ${ }^{1}$ H.B. Zhang ${ }^{1}$, B. Yang ${ }^{2}$, J.F. Yin ${ }^{3}$, S.G. Wei ${ }^{1}$, Y.S. Zhu ${ }^{1}$, X.N. Jia ${ }^{1}$ and S.B. Li $^{1}$

${ }^{1}$ College of Forensic Science, Health Science Center, Xi'an Jiaotong University, Xi'an, China

${ }^{2}$ Department of Clinical Laboratory, The First Affiliated Hospital, Health Science Center, Xi'an Jiaotong University, Xi'an, China

${ }^{3}$ Department of Clinical Laboratory, The Second Affiliated Hospital, Health Science Center, Xi'an Jiaotong University, Xi'an, China

Corresponding author: S.B. Li

E-mail: shbinlee@mail.xjtu.edu.cn

Genet. Mol. Res. 14 (3): 9404-9411 (2015)

Received October 14, 2014

Accepted May 18, 2015

Published August 14, 2015

DOI http://dx.doi.org/10.4238/2015.August.14.4

ABSTRACT. Previous studies have found that the vaccinia related kinase 2 gene ( $V R K 2)$ polymorphism was associated with schizophrenia (SCZ) in the worldwide population. This association was further supported by $V R K 2$ mRNA expression patterns and brain structure variations. Here, we analyzed four single nucleotide polymorphisms (SNPs) of the $V R K 2$ gene in a total population of 893 samples, consisting of 360 patients with SCZ and 533 healthy controls of Han Chinese descent using the SNPscan method. Single SNP, haplotype, and gender-specific association analyses were performed. We found that rs3732136 was significantly associated with SCZ $(\mathrm{P}=0.042$; odds ratio $=1.25 ; 95 \%$ confidence interval $=1.01-1.55)$. Further genotype and haplotype association analyses suggested a similar pattern. Our data provide preliminary evidence that the $V R K 2$ gene might play a 
major role in the development of SCZ in the Northwest Chinese Han population.

Key words: VRK2 gene; SNP; Schizophrenia; Association study

\section{INTRODUCTION}

Schizophrenia (SCZ) is a severe and complex mental disorder that shows positive and negative symptoms such as delusions and hallucinations. This disease has a profound impact on the quality of life and social burden (Monti et al., 2013). The cause of SCZ is likely to be a complex interaction between genetic and environmental factors; it has an estimated heritability of $64-80 \%$ (Thaker and Carpenter, 2001). Due to lack of clear biological markers, diagnosis of SCZ has long been performed based exclusively on clinical signs and symptoms (American Psychiatric Association, 2000). Recent genome-wide association studies (GWAS) and largescale meta-analyses have revealed a set of common variations predisposing to SCZ (Shi et al., 2009; Stefansson et al., 2009; Steinberg et al., 2011; Rietschel et al., 2012). One of the GWAS found that a VRK2 polymorphism was significantly associated with SCZ by analysis of over sixty thousand samples (Ripke, 2011). Researchers have also successfully replicated the association of VRK2 with SCZ in Asian and European populations (Li et al., 2012). Furthermore, they also found a significant association of VRK2 with total brain volume and white matter volume (Wirgenes et al., 2012).

Gene expression analyses using DNA micro-arrays have supported the hypothesis that dysfunctional myelination of neurons might be involved in the pathogenesis of SCZ (Yuan et al., 2012). The expression of VRK2 was shown to be significantly increased in the brains of patients with SCZ. It is possible therefore that genetic variations affecting the expression of the $V R K 2$ gene might also contribute to the susceptibility of individuals to SCZ.

Therefore, $V R K 2$ is likely a common risk gene for $\mathrm{SCZ}$ in the worldwide populations. In order to test whether VRK2 is associated with SCZ in the Northwest Chinese Han population, allele, genotype and haplotype frequencies of four single nucleotide polymorphisms (SNPs) of the VRK2 gene were compared in this study between $\mathrm{SCZ}$ and control populations.

\section{MATERIAL AND METHODS}

\section{Samples}

A total of 893 samples (360 patients with SCZ and 533 normal controls) were enrolled from the Mental Health Center of the First Affiliated Hospital, Xi' an Jiaotong University. All 360 unrelated patients with SCZ (177 men and 183 women, mean age: $37.2 \pm$ 10.4 years) were interviewed independently by two experienced psychiatrists according to DSM-IV diagnostic criteria which included personal history, hospital record, and familyhistory reports. We also collected 533 normal controls (232 men and 301 women, mean age: $35.6 \pm 11.2$ years) from the Medical Examination Center of this hospital. Normal controls were confirmed to have a lack of mental illness and were matched with patients in gender, 
age, origin and educational level, after undergoing health examination. Informed consent was obtained from all participants.

\section{Genotyping}

We identified four SNPs with minor allele frequencies $>0.05$ in the VRK2 gene including intron, exon, and 3' UTR regions in the HapMap HCB database. SNPs reported to be significantly associated with SCZ were also examined in this study (Wirgenes et al., 2012). Overall, rs2312147 in the VRK2 5' UTR, rs1051061 in exonic sequence, rs2043890 in intronic sequence, and rs3732136 in the 3' UTR were chosen for analysis in the present study.

Human genomic DNA was extracted using a standard method according to manufacturer recommendations (Omega Bio-tek, Norcross, GA, USA). Sample DNA (10 ng) was amplified by polymerase chain reaction (PCR). A 48-Plex SNPscan ${ }^{\mathrm{TM}}$ kit (Genesky Biotechnologies Inc., Shanghai, China) was designed and used to determine genotypes of the four SNPs. The SNPscan technique was developed according to patented SNP genotyping technology by Genesky Biotechnologies Inc., which provides a high-throughput and cost-saving SNP genotyping method based on double ligation and multiplex fluorescence PCR as previously described (Du et al., 2014).

The genotyping method is accurate and has been used by many studies (Ren et al., 2014; Wang et al., 2014; Yin et al., 2014). Repeated analyses were performed to guarantee the genotyping quality by randomly choosing $5 \%$ samples with high DNA quality. The average genotype call rate for all markers was $98.2 \%$.

\section{Statistical analysis}

Using the $\mathrm{G}^{*}$ Power program (Franz Faul, University Kiel, Germany), the statistical power of the sample size was calculated according to Cohen's method (Faul et al., 2007). This demonstrated $>85 \%$ power to detect a significant $(\mathrm{P}<0.05)$ association for genotypes, alleles, and haplotypes when an effect size index of 0.1 (corresponding to a "weak" gene effect) was used in our samples.

The genotype, allele, and haplotype frequency differences between patients and controls were calculated by chi-square analysis. The deviation of the genotype counts from HardyWeinberg equilibrium (HWE) was tested by SHEsis (http://analysis.box-X.cn). The odds ratio (ORs) and 95\% confidence interval (CIs) were calculated by unconditional logistic regression of the association between the VRK2 gene and the presence of SCZ. Rare haplotypes (less than $1 \%$ of both patient and control subjects) were excluded from further analysis. Furthermore, stratified analyses were conducted to examine whether differences in gene and gender influenced identified associations. All statistical analyses were performed using the SPSS 18.0 software (SPSS Inc., Chicago, IL, USA).

\section{RESULTS}

No significant deviation from HWE was found in patients or controls for the four SNPs. The frequencies of genotypes and alleles of the four VRK2 SNPs are shown in Table 1. All SNPs 
were highly polymorphic in patients and controls. We first conducted a single SNP association analysis. When all of the samples were considered, we observed a significant association for rs 3732136 $(\mathrm{P}=0.042 ; \mathrm{OR}=1.25 ; 95 \% \mathrm{CI}, 1.01-1.55)$. Genotype association analysis for $\mathrm{rs} 3732136$ suggested a similar pattern with a significant $\mathrm{P}$ value $(\mathrm{P}=0.039)$. When divided according to gender, there was no significant difference in allele and genotype frequencies (Table 2).

Linkage disequilibrium analyses of the patients and controls revealed that the four SNPs were located in one haplotype block (Figure 1). Although some haplotypes (HAP1: $\mathrm{P}=0.039$; HAP4, $\mathrm{P}=0.049$ ) and a gender-specific haplotype (HAP4, $\mathrm{P}=0.006$ in women) showed significant differences between patient and control populations, they did not meet standard significance criteria for haplotype frequencies based on the global $P$ values (Table 3$)$.

\begin{tabular}{|c|c|c|c|c|c|c|c|c|}
\hline \multirow[t]{2}{*}{ SNP } & \multirow[t]{2}{*}{ Genotypes/Alleles } & \multicolumn{2}{|c|}{$\mathrm{SCZ}(\mathrm{N}=360)$} & \multicolumn{2}{|c|}{ CTR $(\mathrm{N}=533)$} & \multirow[t]{2}{*}{ OR } & \multirow[t]{2}{*}{$95 \% \mathrm{CI}$} & \multirow[t]{2}{*}{$P$ value } \\
\hline & & $\mathrm{N}$ & $\%$ & $\mathrm{~N}$ & $\%$ & & & \\
\hline \multirow[t]{7}{*}{ rs $2312147^{\mathrm{a}}$} & $\mathrm{CC}$ & 202 & 56.11 & 284 & 51.36 & 1 & & 0.111 \\
\hline & СТ & 134 & 37.22 & 222 & 40.14 & 1.20 & $0.90-1.58$ & 0.211 \\
\hline & TT & 24 & 6.67 & 47 & 8.50 & 1.39 & $0.83-2.35$ & 0.214 \\
\hline & $\mathrm{CC} v s \mathrm{CT}+\mathrm{TT}$ & & & & & 1.23 & $0.94-1.60$ & 0.134 \\
\hline & $\mathrm{CC}+\mathrm{TC}$ vs $\mathrm{CC}$ & & & & & 0.77 & $0.46-1.29$ & 0.324 \\
\hline & Allele C & 538 & 74.72 & 790 & 71.43 & 1 & & \\
\hline & Allele T & 182 & 25.28 & 316 & 28.57 & 1.19 & $0.96-1.47$ & 0.108 \\
\hline \multirow[t]{7}{*}{ rs $1051061^{\mathrm{b}}$} & AA & 88 & 24.51 & 165 & 29.84 & 1 & & 0.857 \\
\hline & AG & 182 & 50.70 & 265 & 47.92 & 1.14 & $0.73-1.76$ & 0.567 \\
\hline & GG & 89 & 24.79 & 123 & 22.24 & 1.43 & $0.84-2.43$ & 0.187 \\
\hline & $\mathrm{AA} v s \mathrm{AG}+\mathrm{GG}$ & & & & & 1.22 & $0.80-1.84$ & 0.356 \\
\hline & $\mathrm{AA}+\mathrm{AG} v s \mathrm{GG}$ & & & & & 0.76 & $0.49-1.19$ & 0.230 \\
\hline & Allele A & 358 & 49.86 & 595 & 53.80 & 1 & & \\
\hline & Allele G & 360 & 50.14 & 511 & 46.20 & 1.19 & $0.91-1.54$ & 0.201 \\
\hline \multirow[t]{7}{*}{ rs $2043890^{\circ}$} & AA & 211 & 58.77 & 323 & 58.51 & 1 & & 0.837 \\
\hline & AG & 128 & 35.65 & 195 & 35.33 & 1.00 & $0.75-1.32$ & 0.973 \\
\hline & GG & 20 & 5.58 & 34 & 6.16 & 1.11 & $0.62-1.98$ & 0.938 \\
\hline & $\mathrm{AA} v s \mathrm{AG}+\mathrm{GG}$ & & & & & 1.01 & $0.77-1.32$ & 0.938 \\
\hline & $\mathrm{AA}+\mathrm{AG} v s \mathrm{GG}$ & & & & & 0.90 & $0.51-1.59$ & 0.713 \\
\hline & Allele A & 550 & 76.60 & 841 & 76.18 & 1 & & \\
\hline & Allele G & 168 & 23.40 & 263 & 23.82 & 1.02 & $0.82-1.28$ & 0.835 \\
\hline \multirow[t]{7}{*}{ rs $3732136^{d}$} & $\mathrm{CC}$ & 193 & 54.21 & 260 & 48.87 & 1 & & 0.039 \\
\hline & CT & 142 & 39.89 & 221 & 41.54 & 1.16 & $0.87-1.53$ & 0.317 \\
\hline & TT & 21 & 5.90 & 51 & 9.59 & 1.80 & $1.05-3.10$ & 0.038 \\
\hline & $\mathrm{CC} v s \mathrm{CT}+\mathrm{TT}$ & & & & & 1.24 & $0.95-1.62$ & 0.132 \\
\hline & $\mathrm{CC}+\mathrm{CT} v s \mathrm{TT}$ & & & & & 1.69 & $1.00-2.87$ & 0.059 \\
\hline & Allele C & 528 & 74.16 & 741 & 69.64 & 1 & & \\
\hline & Allele $\mathrm{T}$ & 184 & 25.84 & 323 & 30.36 & 1.25 & $1.01-1.55$ & 0.042 \\
\hline
\end{tabular}

${ }^{a}$ One individual failed to be genotyped for rs2312147; btwo individuals failed to be genotyped for rs 1051061; ctwo individuals failed to be genotyped for rs2043890; dfive individuals failed to be genotyped for rs3732136; SNP = single nucleotide polymorphism; $\mathrm{SCZ}=$ schizophrenia; $\mathrm{CTR}=$ control; $\mathrm{OR}=$ odds ratio; $\mathrm{CI}=$ confidence interval. Significant $\mathrm{P}$ values are in italic bold text. 
Table 2. Gender specific allele and genotype association analysis.

\begin{tabular}{|c|c|c|c|c|c|c|c|c|}
\hline \multicolumn{2}{|c|}{ Marks and gender } & \multicolumn{2}{|c|}{ Allele frequency (\%) } & P value & \multicolumn{3}{|c|}{ Genotype frequency (\%) } & $P$ value \\
\hline \multirow{2}{*}{\multicolumn{9}{|c|}{ rs 2312147}} \\
\hline $\mathrm{M}$ & & & & & & & & \\
\hline & $\mathrm{SCZ}$ & 74.72 & 25.28 & \multirow[t]{2}{*}{0.693} & 57.96 & 33.52 & 8.52 & \multirow[t]{2}{*}{0.707} \\
\hline & CTR & 73.49 & 26.51 & & 56.04 & 34.91 & 9.05 & \\
\hline \multicolumn{9}{|l|}{$\mathrm{F}$} \\
\hline & $\mathrm{SCZ}$ & 75.00 & 25.00 & \multirow[t]{2}{*}{0.064} & 54.95 & 40.11 & 4.94 & \multirow[t]{2}{*}{0.056} \\
\hline & CTR & 69.44 & 30.56 & & 47.18 & 44.52 & 8.30 & \\
\hline \multicolumn{9}{|c|}{ rs1051061 } \\
\hline $\mathrm{M}$ & $\mathrm{SCZ}$ & 48.58 & 51.42 & \multirow[t]{2}{*}{0.283} & 23.30 & 50.57 & 26.13 & \multirow[t]{2}{*}{0.299} \\
\hline & CTR & $\begin{array}{l}40.50 \\
52.37\end{array}$ & $\begin{array}{l}1.42 \\
47.63\end{array}$ & & 30.60 & 43.54 & 25.86 & \\
\hline \multicolumn{9}{|l|}{$\mathrm{F}$} \\
\hline & $\mathrm{SCZ}$ & 51.09 & 48.91 & \multirow[t]{2}{*}{0.201} & 25.68 & 50.82 & 23.50 & \multirow[t]{2}{*}{0.194} \\
\hline & CTR & 55.32 & $\begin{array}{l}40.91 \\
44.68\end{array}$ & & 29.57 & 51.50 & $\begin{array}{l}25.50 \\
18.93\end{array}$ & \\
\hline \multicolumn{9}{|c|}{ rs2043890 } \\
\hline $\mathrm{M}$ & $\mathrm{SCZ}$ & 77.27 & 22.73 & \multirow[t]{2}{*}{0.746} & 60.23 & 34.09 & 5.68 & \multirow{2}{*}{0.753} \\
\hline & CTR & 76.30 & 23.70 & & 59.57 & 33.48 & 6.95 & \\
\hline \multicolumn{9}{|l|}{$\mathrm{F}$} \\
\hline & $\mathrm{SCZ}$ & 75.96 & 24.04 & \multirow[t]{2}{*}{0.895} & 57.38 & 37.16 & 5.46 & \multirow[t]{2}{*}{0.894} \\
\hline & CTR & 75.58 & 24.42 & & 56.81 & 37.54 & 5.65 & \\
\hline \multicolumn{9}{|c|}{ rs3732136 } \\
\hline $\mathrm{M}$ & SCZ & 75.00 & 25.00 & \multirow[t]{2}{*}{0.219} & 55.17 & 39.66 & 5.17 & \multirow[t]{2}{*}{0.213} \\
\hline & CTR & 71.12 & 28.88 & & 50.43 & 41.38 & 8.19 & \\
\hline F & $\mathrm{SCZ}$ & 73.35 & 26.65 & 0.105 & 53.30 & 40.11 & 6.59 & 0.108 \\
\hline
\end{tabular}

$\mathrm{SCZ}=$ schizophrenia; $\mathrm{CTR}=$ control; $\mathrm{M}=$ male; $\mathrm{F}=$ female.

A

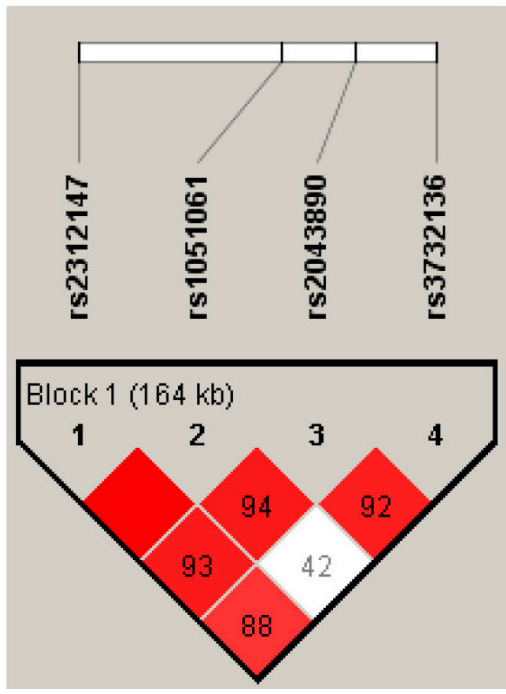

B

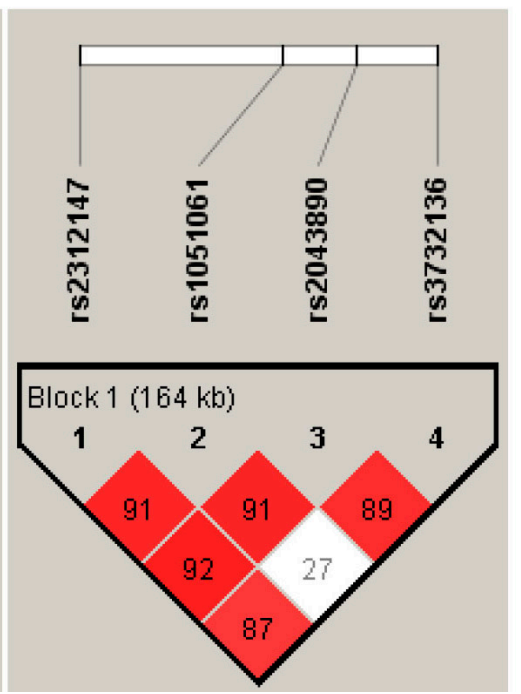

Figure 1. Linkage disequilibrium (LD) plot of the four SNPs in the VRK2 gene in patients and controls (below). Values in squares are the pair-wise calculation of D'. Empty squares indicate D' $=1$ (i.e. complete LD between a pair of SNPs). LD, linkage disequilibrium; SNP, single nucleotide polymorphism. A. Patients; B. controls. 
Table 3. Haplotype frequencies and association analysis.

\begin{tabular}{|c|c|c|c|c|c|c|c|c|}
\hline \multirow{2}{*}{$\begin{array}{l}\text { Haplotype } \\
\text { ID }\end{array}$} & \multirow[t]{2}{*}{ SNP1 } & \multirow[t]{2}{*}{ SNP2 } & \multirow[t]{2}{*}{ SNP3 } & \multirow[t]{2}{*}{ SNP4 } & \multicolumn{4}{|c|}{ Gene counting (frequency \%) } \\
\hline & & & & & SCZ & CTR & $P$ value & Global \\
\hline HAP1 & $\mathrm{C}$ & G & A & $\mathrm{C}$ & 48.5 & 43.5 & 0.039 & 0.241 \\
\hline HAP2 & $\mathrm{C}$ & A & A & $\mathrm{T}$ & 21.1 & 22.9 & 0.362 & \\
\hline HAP3 & $\mathrm{T}$ & A & G & C & 20.5 & 21.1 & 0.775 & \\
\hline HAP4 & $\mathrm{T}$ & A & A & $\mathrm{T}$ & 3.8 & 5.9 & 0.049 & \\
\hline HAP5 & $\mathrm{C}$ & A & A & C & 2.42 & 1.64 & 0.245 & \\
\hline HAP6 & $\mathrm{C}$ & A & G & C & 1.94 & 1.8 & 0.890 & \\
\hline \multicolumn{9}{|l|}{ Male } \\
\hline HAP1 & $\mathrm{C}$ & G & A & $\mathrm{C}$ & 50.2 & 45.4 & 0.168 & 0.766 \\
\hline HAP2 & $\mathrm{C}$ & A & A & $\mathrm{T}$ & 19.9 & 23.5 & 0.221 & \\
\hline HAP3 & $\mathrm{T}$ & A & G & $\mathrm{C}$ & 19.3 & 19.9 & 0.855 & \\
\hline HAP4 & $\mathrm{T}$ & A & A & $\mathrm{T}$ & 4.6 & 4.3 & 0.832 & \\
\hline HAP5 & $\mathrm{C}$ & A & A & $\mathrm{C}$ & 2.3 & 1.6 & 0.489 & \\
\hline HAP6 & C & A & G & C & 2.4 & 2.2 & 0.856 & \\
\hline \multicolumn{9}{|l|}{ Female } \\
\hline HAP1 & C & G & A & C & 46.8 & 42.1 & 0.149 & 0.264 \\
\hline HAP2 & C & A & A & $\mathrm{T}$ & 22.2 & 22.5 & 0.938 & \\
\hline HAP3 & $\mathrm{T}$ & A & G & C & 21.6 & 22.0 & 0.890 & \\
\hline HAP4 & $\mathrm{T}$ & A & A & $\mathrm{T}$ & 3.0 & 7.2 & 0.006 & \\
\hline HAP5 & C & A & A & C & 2.5 & 1.7 & 0.391 & \\
\hline HAP6 & $\mathrm{C}$ & A & G & $\mathrm{C}$ & 1.5 & 1.6 & 0.870 & \\
\hline
\end{tabular}

$\overline{\mathrm{SNP}}=$ single nucleotide polymorphism; $\mathrm{SCZ}=$ schizophrenia; $\mathrm{CTR}=$ control. Significant $\mathrm{P}$ values are in italic bold text.

\section{DISCUSSION}

In this research, we present a case-control study of four polymorphisms (rs2312147, rs1051061, rs2043890, and rs3732136) of the VRK2 gene including 533 controls and 360 patients with SCZ from the Northwest Chinese Han population. In this association study, we found that the $\mathrm{C}$ allele and the CC genotype of the VRK2 rs3732136 SNP were associated with a decreased risk of SCZ. This significant association was not reflected by other SNPs (rs1051061, rs2043890, etc.) that showed high linkage disequilibrium with rs3732136 (Figure 1). To the best of our knowledge, this is the first report of a significant association of the rs 3732136 polymorphism with SCZ. Although the significance is uncertain, we note that SNP rs3732136 is located in intron 1 of the FANCL gene as well as in the alternative exon16 of the VRK2 gene.

FANCL is a member of the FANC gene family, and disruption of the function of FANC genes causes Fanconi anemia (FA) (Alpi and Patel, 2009). Studies have reported that FANC genes might have a role in the recognition or repair of DNA damage due to the increased risk of cancer seen in patients with FA (Juko-Pecirep et al., 2011). Compared with the study performed in the FANCL gene rs3732136 locus, the frequency of rs3732136 C allele was shown to be $70.1 \%$ in healthy Swedish subjects (Juko-Pecirep et al., 2011), 69.8\% in the French population (St-Laurent Pedneault, 2013), vs $69.6 \%$ in the control population in our study.

The serine/threonine-protein kinase VRK2 is an enzyme encoded by the VRK2 gene, which is located on human chromosome 2p16.1. There have been eight VRK2 isoforms described which arise because of alternatively spliced transcripts of the VRK2 gene (Blanco et al., 2006). VRK2 is widely expressed in human tissues and has increased expression in highly proliferative cells (Nezu et al., 1997).

Although previous studies revealed that the VRK2 rs2312147 polymorphism was associated with SCZ in Asian and European samples, our results did not support these findings. Compared with the study performed in the Chinese Yunnan population, the frequency of the 
rs $2312147 \mathrm{C}$ allele in our study (71.4\% in controls and $74.7 \%$ in patients) was comparable (Wirgenes et al., 2012) (68\% in controls and $74 \%$ in patients with SCZ), whereas the $\mathrm{C}$ allele frequency was much lower in European Americans (61\% in controls and 63\% in patients with SCZ) (Steinberg et al., 2011).

It should be noted that our study participants were all recruited from Shaanxi Province, while the study samples from Li et al. (2012) were drawn from Yunnan Province, and the Steinberg et al. (2011) samples were collected from European Americans. It is therefore possible that differences in the VRK2 polymorphism profiles could reflect regional differences not generalizable to all people. Multiple additional factors might contribute to the variable results as well, including cohort homogeneity, sample size, ethnic background-specific effects, epistasis, and notably the selection pattern of genetic loci.

Taken together, we investigated whether four SNPs (rs2312147, rs1051061, rs2043890, and rs3732136) of the VRK2 were associated with SCZ in the Northwest Chinese Han population. We found that the rs 3732136 polymorphism of the VRK2 gene was associated with SCZ $(\mathrm{P}=0.042)$. These results suggested that $\mathrm{rs} 3732136$ might be associated with the susceptibility to SCZ. However, positive associations might sometimes be due to genetic heterogeneity, and protective alleles might vary according to ethnic differences. Therefore, further studies using a larger number of subjects in different ethnic groups should be performed to determine whether the VRK2 gene polymorphism might be truly involved in the development of SCZ.

\section{ACKNOWLEDGMENTS}

Research supported by the National Natural Science Foundation of China (Grant \#31301949), the National Science Foundation for Post-doctoral Scientists of China (Grant \#2013M532056), and the National Science Foundation for Post-doctoral Scientists of Shaanxi.

\section{REFERENCES}

Alpi AF and Patel KJ (2009). Monoubiquitylation in the Fanconi anemia DNA damage response pathway. DNA Repair (Amst). 8: 430-435.

American Psychiatric Association (2000). Diagnostic and statistical manual of mental disorders (Fourth ed., Text Revision). American Psychiatric Press, Washington, D.C. [DSM-IV-TR].

Blanco S, Klimcakova L, Vega FM and Lazo PA (2006). The subcellular localization of vaccinia-related kinase-2 (VRK2) isoforms determines their different effect on p53 stability in tumour cell lines. FEBS J. 273: 2487-2504.

Du W, Cheng J, Ding H, Jiang Z, et al. (2014). A rapid method for simultaneous multi-gene mutation screening in children with nonsyndromic hearing loss. Genomics 104: 264-270.

Faul F, Erdfelder E, Lang AG, Buchner A. (2007). G*Power 3: a flexible statistical power analysis program for the social, behavioral, and biomedical sciences. Behav. Res. Methods. 39: 175-191.

Juko-Pecirep I, Ivansson EL and Gyllensten UB (2011). Evaluation of Fanconi anaemia genes FANCA, FANCC and FANCL in cervical cancer susceptibility. Gynecol. Oncol. 122: 377-381.

Li M, Wang Y, Zheng XB, Ikeda M, et al. (2012). Meta-analysis and brain imaging data support the involvement of VRK2 (rs2312147) in schizophrenia susceptibility. Schizophr. Res. 142: 200-205.

Monti JM, BeHammam AS, Pandi-Perumal SR, Bromundt V. et al. (2013). Sleep and circadian rhythm dysregulation in schizophrenia. Prog. Neuropsychopharmacol. Biol. Psychiatry 43: 209-216.

Nezu J, Oku A, Jones MH and Shimane M (1997). Identification of two novel human putative serine/threonine kinases, VRK1 and VRK2, with structural similarity to vaccinia virus B1R kinase. Genomics 45: 327-331.

Ren Z, Li M, Liu R, Wang Y, et al. (2014). Interleukin 17A rs3819024 A>G polymorphism is associated with an increased risk of gastric cardia adenocarcinoma in a Chinese population. Biomarkers 19: 411-416.

Rietschel M, Matthiesen M, Degenhardt F, Genetic Risk, et al. (2012). Association between genetic variation in a region on chromosome 11 and schizophrenia in large samples from Europe. Mol. Psychiatry 17: 906-917.

Ripke S, Sanders AR, Kendler KS, Levinson DF, et al. (2011). Schizophrenia Psychiatric Genome Wide Association 
Study (GWAS) Consortium. Genome-wide association study identifies five new schizophrenia loci. Nat. Genet. 43: 969-976.

Shi J, Levinson DF, Duan J, Sanders AR, et al. (2009). Common variants on chromosome 6p22.1 are associated with schizophrenia. Nature 460: 753-757.

St-Laurent Pedneault C, Plourde K, Bélanger S, Ouellette G, et al. (2013). Regulated expression of a FANCL splicing variant as a potential modifier of DNA repair activity. J. Genet. Syndr. Gene Ther. 4: 143.

Stefansson H, Ophoff RA, Steinberg S, Andreassen OA, et al. (2009). Common variants conferring risk of schizophrenia. Nature 460: 744-747.

Steinberg S, de Jong S, Irish Schizophrenia Genomics Consortium, Andreassen OA, et al. (2011). Common variants at VRK2 and TCF4 conferring risk of schizophrenia. Hum. Mol. Genet. 20: 4076-4081.

Thaker GK and Carpenter WT Jr. (2001). Advances in schizophrenia. Nat. Med. 7: 667-671.

Wang X, Yin J, Zheng L, Wang L, et al. (2014). The variant interleukin $1 \mathrm{f} 7 \mathrm{rs} 3811047 \mathrm{G}>\mathrm{A}$ was associated with a decreased risk of gastric cardiac adenocarcinoma in a Chinese Han population. Tumour Biol. 35: 3509-3515.

Wirgenes KV, Sønderby IE, Haukvik UK, Mattingsdal M, et al. (2012). TCF4 sequence variants and mRNA levels are associated with neurodevelopmental characteristics in psychotic disorders. Transl. Psychiatry 2: e112.

Yin J, Wang X, Wei J, Wang L, et al. (2014). Interleukin 12B rs3212227 T > G polymorphism was associated with an increased risk of gastric cardiac adenocarcinoma in a Chinese population. Dis. Esophagus (epub ahead of print). doi: $10.1111 /$ dote/12189

Yuan A, Yi Z, Wang Q, Sun J, et al. (2012). ANK3 as a risk gene for schizophrenia: new data in Han Chinese and meta analysis. Am. J. Med. Genet. B Neuropsychiatr. Genet. 159B: 997-1005. 